\title{
Improvements in population-based survival of patients presenting with metastatic rectal cancer in the south of the Netherlands, 1992-2008
}

\author{
V. E. P. P. Lemmens $\cdot$ N. de Haan • \\ H. J. T. Rutten • H. Martijn • O. J. L. Loosveld • \\ R. M. H. Roumen • G. J. M. Creemers
}

Received: 13 September 2010/ Accepted: 21 December 2010/Published online: 5 January 2011

(C) The Author(s) 2011. This article is published with open access at Springerlink.com

\begin{abstract}
We analysed population-based treatment and survival data of patients who presented with metastatic rectal cancer. All patients diagnosed with primary synchronous metastatic rectal cancer between 1992 and 2008 in the Eindhoven Cancer Registry area were included. Date of diagnosis was divided into three periods (1992-1999, 2000-2004, 2005-2008) according to the availability of chemotherapy type. We assessed treatment patterns and overall survival according to period of diagnosis. The proportion of patients diagnosed with stage IV disease increased from $16 \%$ in $1992-1999$ to $20 \%$ in $2005-2008(P<0.0001)$.
\end{abstract}

V. E. P. P. Lemmens $(\varangle)$

Department of Research, Comprehensive Cancer Centre South,

Eindhoven, The Netherlands

e-mail: v.lemmens@ikz.nl

V. E. P. P. Lemmens

Department of Public Health, Erasmus MC University Medical

Centre, Rotterdam, The Netherlands

N. de Haan · G. J. M. Creemers

Department of Internal Medicine, Catharina Hospital,

Eindhoven, The Netherlands

\section{H. J. T. Rutten}

Department of Surgery, Catharina Hospital,

Eindhoven, The Netherlands

\section{H. Martijn}

Department of Radiotherapy, Hospital, Eindhoven,

The Netherlands

O. J. L. Loosveld

Department of Internal Medicine, Amphia Hospital,

Breda, The Netherlands

R. M. H. Roumen

Department of Surgery, Maxima Medical Centre,

Veldhoven, The Netherlands
Chemotherapy use increased from 5\% in 1992 to $61 \%$ in 2008 $(P<0.0001)$. Resection rates of the primary tumour decreased from $65 \%$ in 1992 to $27 \%$ in $2008(P<0.0001)$, while metastasectomy rates remained constant since 1999 (9\%). Median survival increased from 38 weeks (95\% confidence interval (CI) 32-44) in 1992-1999 to 53 weeks (95\% CI 48-61) in 2005-2008. Among patients not receiving chemotherapy median survival remained approximately 30 weeks. Multivariable analysis confirmed the lower risk of death among patients diagnosed in more recent years. Increased use of chemotherapy went together with improved median survival among patients with metastatic rectal cancer in the last two decades. Stage migration as an effect of more effective imaging procedures is likely to be partly responsible for this improved survival.

Keywords Chemotherapy $\cdot$ Metastases ·

Population-based cancer registries - Rectal cancer .

Survival

$\begin{array}{ll}\text { Abbreviations } \\ \text { ECR } & \text { Eindhoven cancer registry } \\ \text { TNM } & \text { Tumour node classification } \\ \text { ICD-O } & \text { International classification of disease-oncology } \\ \text { SES } & \text { Socioeconomic status } \\ \text { 5-FU } & \text { 5-Fluoruracil } \\ \text { HR } & \text { Hazard ratio } \\ \text { CL } & \text { Confidence limits }\end{array}$

\section{Introduction}

Colorectal cancer is one of the leading causes of cancer worldwide. It is the third most common type of cancer in 
men in the Netherlands (14\%) and the second most common type of cancer in women (13\%). In 2008 in the Netherlands, 12,127 new cases of colorectal cancer were diagnosed [1]. Of these, 3,986 were rectal cancers. Primary treatment for resectable rectal carcinoma is surgical resection in combination with preoperative radiotherapy [2]. One fifth of patients with rectal cancer in the Netherlands present with metastatic disease [3], and treatment is palliative for patients with non-resectable metastases [4]. For years, 5-fluorouracil (5-FU) based chemotherapy remained the cornerstone of chemotherapy in colorectal cancer. Since 2000, with the introduction of the new agents oxaliplatin and irinotecan and from 2005 with combination of chemotherapy with targeted therapy drugs, such as bevacizumab and cetuximab response rate and overall survival data further improved [5-11].

Recently, we published population-based survival data of patients who presented with metastatic colon cancer at diagnosis in the period from 1990 to 2004 [12]. Remarkably, the survival of patients who did not receive palliative chemotherapy remained only 22 weeks. Survival of patients receiving chemotherapy increased, however, from 54 weeks in the period 1990-1994 to 72 weeks in 2003-2004. Patients who presented with metastatic rectal cancer might differ from colon cancer with respect to (presenting) symptoms, treatment and biological behaviour [13]. In this study we report the results of the populationbased survival data of the patients who presented with metastatic rectal cancer in the period from 1992 until 2008 in the south of the Netherlands.

\section{Methods}

Population-based data from the Eindhoven Cancer Registry (ECR) was used, which is maintained by the Comprehensive Cancer Centre South. The ECR records data on all patients newly diagnosed with cancer in the southern part of the Netherlands, an area with 2.3 million inhabitants. The ECR is served by 10 community hospitals, six pathology departments, and two radiotherapy institutes. Data on patient characteristics like gender, date of birth, and postal code and tumour characteristics like date of diagnosis, tumour type, histology, subsite, stage, and treatment are routinely extracted from the medical records by trained registrars. The quality of the data is consistent due to thorough training of the registration clerks and computerised consistency checks at regional and national level. The completeness of the registration is estimated to exceed $95 \%$.

All patients diagnosed with primary metastatic cancer of the rectum or rectosigmoid junction (anatomical tumour location C19-C20, according to the International Classification of Diseases for Oncology ICD-O-3 [14]) from 1992 to 2008 in the registration area of the ECR were included $(n=1,319)$. Patients with cancer diagnosed at autopsy were excluded. Stage of the disease was defined according to tumour-lymph node-metastasis (TNM) classification [15]. Data on localisation of metastases were available on organ level, also in case of multiple locations in different organs. No information was available on the number of metastatic lesions within an organ, nor on the size of the metastatic lesions. Chemotherapy (yes versus no) was defined as prescription of any chemotherapy at initial diagnosis and up to 6 months after. Date of diagnosis was divided into three periods according to the availability of chemotherapy for metastatic rectal cancer patients: 1992-1999 (period in which a relatively small part of patients with metastatic rectal cancer received chemotherapy), 2000-2004 (main treatment remained 5-FU based therapy), and 2005-2008 (combination therapy more generally used, also due to the CAIRO study [16], including increased use of targeted therapy drugs). Radiotherapy was defined as radiotherapy directed at the primary tumour, or directed at metastases, where appropriate. Surgery was defined as resection of the primary tumour, or as metastasectomy (resection of metastases in any organ), where appropriate.

Prognostically relevant concomitant conditions are recorded from the medical records according to a slightly adapted version of the Charlson Index, on a routine basis since 1995 [17, 18]. Socio-economic status (SES) of the patient was defined at neighborhood level (based on postal code of residence area, 17 households on average) combining mean household income and mean value of the house/apartment [19]. The latter was derived from individual fiscal data made available at an aggregated level. Postal codes were assigned to one of 3 SES categories: low (1st-3rd decile), intermediate (4th-7th decile), and high (8th-10th decile). For patients residing in nursing homes, a special SES category was assigned.

Differences in the receipt of chemotherapy between periods of diagnosis and between patient and tumour factors were tested for by means of a $\chi^{2}$ test. A multivariable logistic regression analysis was performed in order to identify the independent influence of the aforementioned factors.

Follow-up of vital status of all patients was complete up to 1 January 2010. In addition to passive follow-up via the hospitals, this information was actively obtained from the municipal personal records database. Crude survival rates were computed according to patient and tumour characteristics. Survival time was defined as the time from diagnosis to death or 1 January 2010 for the patients who were still alive. A log-rank test was carried out to evaluate significant differences between survival curves. A multivariable proportional hazards regression analysis 
was used to discriminate independent risk factors for death. To investigate the effect of treatment on any improvement in survival over time, a model including and a model excluding the various treatment options was built. SAS/ STAT statistical software (SAS system 9.1, SAS Institute, Cary, NC) was used for the analyses.

\section{Results}

The proportion of patients with rectal cancer diagnosed with synchronous metastases (stage IV) increased from $16 \%$ in $1992-1999$ to $20 \%$ in $2005-2008(P<0.0001)$ (Table 1).

Table 1 Proportion of patients with rectal cancer diagnosed with synchronous metastases (stage IV), as a proportion of stage I-IV patients diagnosed with rectal cancer between 1992 and 2008 in the south of the Netherlands, by period of diagnosis

\begin{tabular}{ll}
\hline Period of diagnosis & Proportion M1 at diagnosis $(\%)$ \\
\hline $1992-1999$ & 16 \\
$2000-2004$ & 19 \\
$2005-2008$ & $20^{\mathrm{a}}$
\end{tabular}

$\overline{{ }^{a}} \chi^{2}$ test of difference in stage distribution between periods of diagnosis, $P$-value $<0.0001$
Overall, the proportion of patients treated with chemotherapy increased from $27 \%$ in $1992-1999$ to $58 \%$ in 2005-2008 $(P<0.0001)$ (Table 2$)$. Both among younger and older patients administration of chemotherapy increased, although large age-related differences remained. Patients with a high socio-economic status (SES) and those without comorbidity more frequently received chemotherapy, as did male patients in the most recent period.

Chemotherapy rates by year of diagnosis are depicted in Fig. 1a, showing the apparent increase over time $(61 \%$ in 2008) $(P<0.0001)$. As can be seen in the same figure, resection rates of the primary tumour decreased from $65 \%$ in 1992 to $27 \%$ in $2008(P>0.0001)$. Metastasectomy rates increased until 1999 up to $9 \%$, and remained relatively stable afterwards $(P=0.3)$. In Fig. $1 \mathrm{~b}$, trends in referral for radiotherapy are depicted. Radiotherapy rates directed at the primary tumour, not preceded or followed by a resection, also remained relatively constant over time, while pre- or postoperative radiotherapy rates increased up to 2002, and declined after 2004, coupled to the lower resection rates in these years $(P<0.0001)$.

Crude overall survival rates improved between the first two periods, and remained stable in 2005-2008 (Fig. 2). Median survival increased from 38 weeks (CL 32-44) in 1992-1999 to 50 weeks in 2000-2005 (CL 45-59), and to 53 weeks (CL 48-61) in 2005-2008 (Table 3). Median
Table 2 General characteristics including proportion of patients receiving chemotherapy $(\mathrm{CT})$

\footnotetext{
a Registered since 1993; patients diagnosed in 1992 designated to 'unknown comorbidity'

b $\chi^{2}$ test of difference in chemotherapy use between periods of diagnosis

* $P$-value $>0.05\left(\chi^{2}\right.$ test of difference in chemotherapy use between values of one variable within the same period of diagnosis, excluding unknown category)

** $P$-value $>0.01\left(\chi^{2}\right.$ test of difference in chemotherapy use between values of one variable within the same period of diagnosis, excluding unknown category)
}

\begin{tabular}{|c|c|c|c|c|c|c|}
\hline & \multicolumn{2}{|c|}{ 1992-1999 } & \multicolumn{2}{|c|}{ 2000-2004 } & \multicolumn{2}{|c|}{ 2005-2008 } \\
\hline & $n$ & $\mathrm{CT}(\%)$ & $n$ & $\mathrm{CT}(\%)$ & $n$ & $\mathrm{CT}(\%)$ \\
\hline Overall & 415 & 27 & 456 & 47 & 448 & $58 * * \mathrm{~b}$ \\
\hline \multicolumn{7}{|l|}{ Age } \\
\hline$<70$ & 243 & 37 & 283 & 61 & 251 & 76 \\
\hline $70+$ & 172 & $12 * *$ & 173 & $24 * *$ & 197 & $36^{* *}$ \\
\hline \multicolumn{7}{|l|}{ Gender } \\
\hline Male & 261 & 29 & 281 & 47 & 281 & 62 \\
\hline Female & 154 & 24 & 175 & 46 & 167 & $52 *$ \\
\hline \multicolumn{7}{|l|}{ Socio-economic status } \\
\hline Low & 92 & 21 & 125 & 39 & 126 & 56 \\
\hline Intermediate & 169 & 31 & 190 & 50 & 1778 & 58 \\
\hline High & 116 & 30 & 115 & 56 & 123 & 64 \\
\hline Institutionalised & 22 & 9 & 17 & $18^{* *}$ & 11 & $0 * *$ \\
\hline Unknown & 16 & 25 & 9 & 22 & 11 & 73 \\
\hline \multicolumn{7}{|l|}{ Comorbidity $^{\mathrm{a}}$} \\
\hline None & 174 & 34 & 168 & 54 & 150 & 69 \\
\hline One comorbid condition & 116 & 25 & 135 & 47 & 127 & 58 \\
\hline Two or more comorbid conditions & 62 & 19 & 98 & $34 * *$ & 135 & $47 * *$ \\
\hline Unknown & 63 & 19 & 55 & 49 & 36 & 53 \\
\hline \multicolumn{7}{|l|}{ Site of metastasis } \\
\hline Liver only & 255 & 29 & 261 & 50 & 237 & 58 \\
\hline Other & 160 & 24 & 195 & 43 & 211 & 58 \\
\hline
\end{tabular}



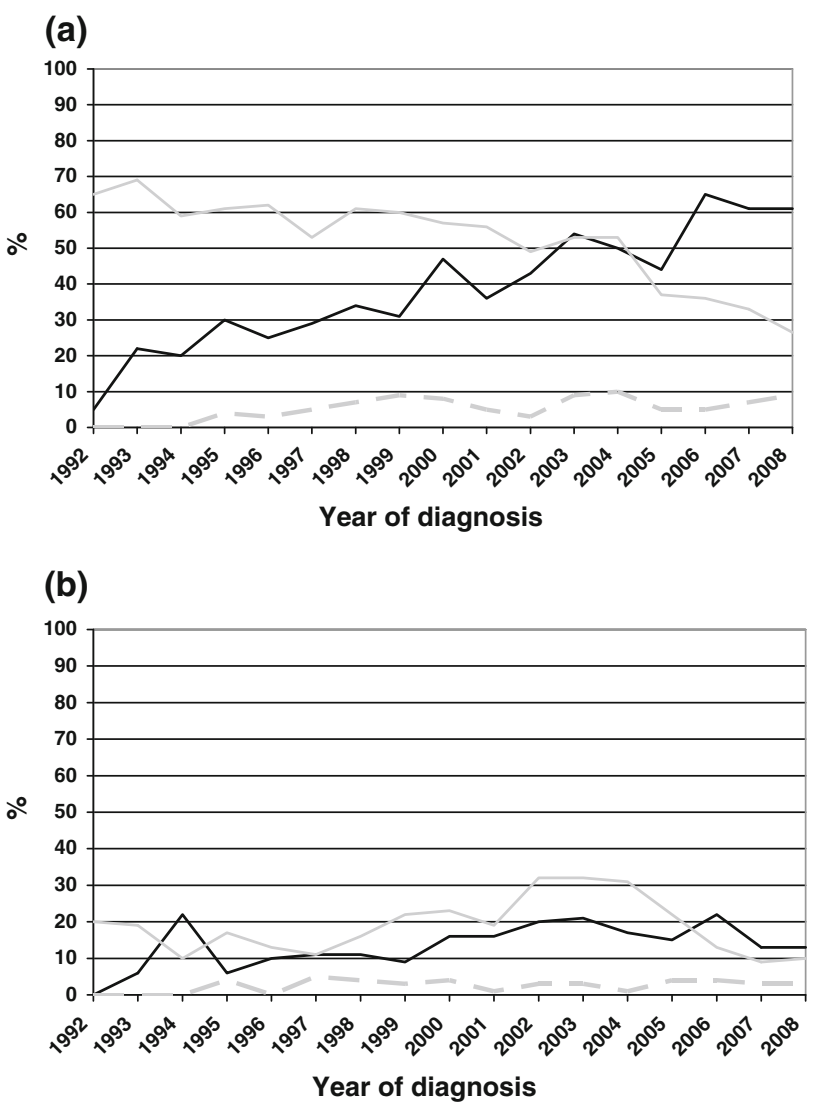

Fig. 1 Trend in treatment of patients with rectal cancer and synchronous metastases in the south of the Netherlands, 1992-2006. a Chemotherapy and resection (black line Chemotherapy, grey line Resection of primary tumour, dashed grey line Metastasectomy). b Radiotherapy (black line Radiotherapy without resection (primary tumour), grey line pre- or postoperative radiotherapy (primary tumour), dashed grey line radiotherapy (metastases))

survival of patients receiving chemotherapy also showed an increasing trend until 2000-2004 without any further improvement afterwards, although confidence limits overlapped throughout the whole study period. For patients with metastases confined to the liver, an improving trend could be noted from 41 weeks in 1992-1999 to 67 weeks in 2000-2004. Afterwards, median survival remained constant for these patients. Median survival of patients who were not treated with chemotherapy remained dismal over time, at around 30 weeks. In Table 4, median survival is depicted according to patient characteristics.

The improvement in median survival seen in Table 3 seems to be largely caused by improved survival among patients aged 70 or younger (from 46 to 73 weeks). Median survival remained constant among older patients. Remarkably, the increase in median survival was larger among males compared to females, especially in the most recent period (median survival 2005-2008: males 62 (53-72) weeks; females 42 (29-51) weeks.

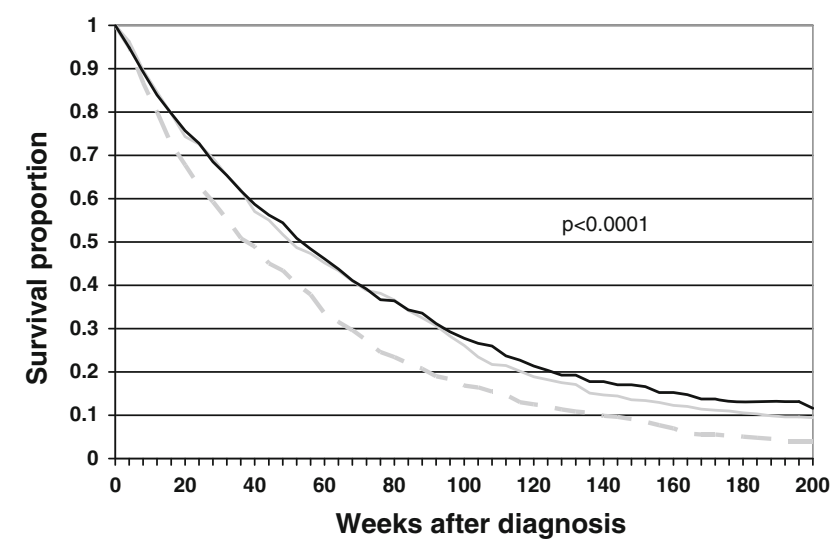

Fig. 2 Crude survival (in weeks) of patients with rectal cancer and synchronous metastases in the south of the Netherlands, by period of diagnosis. dashed grey line 1992-1999, grey line 2000-2004, black line 2005-2008

In Table 5, the results of a multivariable proportional hazards regression analysis are shown. After adjustment for all variables listed including not only various modes of treatment but also SES and anatomic sublocalisation, a lower risk of death could be observed for patients diagnosed in more recent years. Furthermore, of prognostic value were age, presence of comorbidity, depth of penetration, nodal status, localisation of metastases, chemotherapy use, metastasectomy, and radiotherapy directed at the primary tumour. Undergoing a resection of the primary tumour was of borderline statistical significance. Although after inclusion of treatment variables (model 2) the effect of period of diagnosis decreased somewhat compared to the model without adjustment for treatment (model 1), a significant effect of period of diagnosis remained, which means that other factors besides treatment were likely to be partly responsible for the decreased risk of death observed in more recent years, such as stage migration.

\section{Discussion}

In this population-based study we investigated the survival of patients presenting with metastatic rectal cancer in the south of the Netherlands between 1992 and 2008. The proportion of patients presenting with stage IV rectal cancer in the Eindhoven Cancer Registry increased from $16 \%$ in the period $1992-1999$ to $20 \%$ in the period 2005-2008. The most probable explanation of this phenomenon is stage migration. In the last decennium the diagnostic work-up for rectal cancer has changed dramatically, with standard use of procedures like MRI and/or endo-echography of the rectum and CT scan of thorax and abdomen to exclude metastasis. Stage migration is important to consider when interpreting any stage specific 
Table 3 Median survival (in weeks) of patients with rectal cancer and synchronous metastases, according to receipt of chemotherapy, and separately for patients with metastases confined to the liver, by period of diagnosis

$C L$ confidence limits

\begin{tabular}{lllll}
\hline & \multicolumn{2}{l}{ Median survival in weeks (CL) } & \\
\cline { 2 - 5 } & All patients & $\begin{array}{l}\text { Patients } \\
\text { receiving } \\
\text { chemotherapy }\end{array}$ & $\begin{array}{l}\text { Patients with } \\
\text { metastases } \\
\text { confined to liver }\end{array}$ & $\begin{array}{l}\text { Patients not } \\
\text { receiving } \\
\text { chemotherapy }\end{array}$ \\
\hline $1992-1999$ & $38(32-44)$ & $67(56-76)$ & $41(32-51)$ & $29(24-35)$ \\
$2000-2004$ & $50(45-59)$ & $79(65-91)$ & $67(57-80)$ & $33(27-39)$ \\
$2005-2008$ & $53(48-61)$ & $75(66-89)$ & $64(53-75)$ & $25(19-31)$ \\
\hline
\end{tabular}

Table 4 Median survival (in weeks) of patients with rectal cancer and synchronous metastases, according to patient characteristics, by period of diagnosis

\begin{tabular}{|c|c|c|c|c|c|c|c|c|c|c|}
\hline & \multicolumn{10}{|c|}{ Median survival in weeks (CL) } \\
\hline & \multicolumn{2}{|l|}{ Age } & \multicolumn{2}{|l|}{ Gender } & \multicolumn{3}{|c|}{ Socio-economic status } & \multicolumn{3}{|l|}{ Comorbidity } \\
\hline & $<70$ & $70+$ & Male & Female & Low & $\begin{array}{l}\text { Inter- } \\
\text { mediate }\end{array}$ & High & None & $\begin{array}{l}\text { One } \\
\text { comorbid } \\
\text { condition }\end{array}$ & $\begin{array}{l}\geq \text { Two } \\
\text { comorbid } \\
\text { conditions }\end{array}$ \\
\hline 1992-1999 & $46(39-57)$ & $28(21-35)$ & $36(28-45)$ & $39(32-48)$ & $38(29-45)$ & $41(29-51)$ & $40(27-57)$ & $45(36-35)$ & $33(25-51)$ & $33(19-40)$ \\
\hline $2000-2004$ & $65(53-78)$ & $34(28-40)$ & $50(40-64)$ & $51(43-64)$ & $47(35-57)$ & $52(40-65)$ & $63(45-81)$ & $63(49-77)$ & $49(39-65)$ & $36(26-49)$ \\
\hline $2005-2008$ & $73(59-89)$ & $34(27-42)$ & $62(53-72)$ & $42(29-51)$ & $51(37-61)$ & $56(47-69)$ & $60(48-71)$ & $71(49-91)$ & $53(36-66)$ & $49(37-58)$ \\
\hline
\end{tabular}

$C L$ confidence limits

improvements in cancer [20]. Of interest is that in our study, the overall survival in patients not receiving chemotherapy remained stable over time at about 30 weeks, which is longer in comparison to other published series in metastatic colorectal cancer, including our data on stage IV colon cancer showing survival of 22 weeks [12]. This survival benefit in stage IV rectal cancer might be caused by a more early diagnosis of rectal cancer due to more alarming symptoms (e.g. rectal bleeding, tenesmus, incomplete defecation) and thus lower tumor load at time of diagnosis resulting in a prolonged survival. Another explanation could be the fact that rectal cancer has a different biological behavior. Different genetic abnormalities have been found in colorectal cancers from different sites. Proximal colon cancer is usually related to the nucleotide instability pathway, as microsatellite instability (MSI) and distal cancer are associated with special chromosomal instability (CIN). These differences might be partially explained by different embryological development and physiological circumstances. [13, 21, 22] Also environmental factors such as diet and alcohol influence the development of tumors at different sites of the colorectum [22]. The possible different biological behavior of rectal cancer might partly explain the lower effectiveness of adjuvant chemotherapy in non-metastatic rectal cancer.

Our study showed that the median overall survival of metastatic rectal cancer patients increased significantly from 38 weeks in the period 1992-1999 to 53 weeks in the period 2005-2008. Among patients receiving chemotherapy the median survival was about 75 weeks. The use of palliative chemotherapy kept increasing until 2006, and remained constant afterwards at $60-65 \%$. For patients older than 70 years there was a threefold increase from $12 \%$ to 36\% between 1992-1999 and 2005-2008. It can be speculated that this remarkable increase in the use of chemotherapy among older patients suggests that these patients are increasingly reasonably fit with limited tumor related symptoms. However, there may also be an increased awareness of the benefits of palliative chemotherapy by the oncologist, patient and family.

For patients receiving chemotherapy since 2000 the median overall survival remained constant, despite the use of more and newer cytostatic drugs and biological therapies in recent years. This might partly be caused by the rather limited number of patients (despite the population-based nature of our study), but might also indicate that at population level, patients with metastatic rectal cancer do not benefit from the availability of oxaliplatin and targeted therapies in addition to 5-FU-based treatment. It is possible that a relatively large proportion of the patients did not receive combination chemotherapy, but unfortunately, we only had data available on whether a patient received chemotherapy, not on the type or combinations of chemotherapy. Among patients with metastases confined to the liver, median overall survival also seemed to level off after 2000. A possible explanation for the improved survival of patients with metastases confined to the liver compared to the $1990 \mathrm{~s}$ may be an improved outcome after liver resection [23, 24], and an increased proportion of patients becoming eligible for curative liver resection after 
Table 5 Multivariable proportional hazards regression analyses for patients diagnosed with synchronous metastatic rectal cancer in the south of the Netherlands, 1992-2008 a Adjusted for all listed variables including socioeconomic status and anatomic sublocalisation (rectosigmoid junction vs. rectum)

b Reference category

\begin{tabular}{|c|c|c|c|c|}
\hline & \multicolumn{2}{|c|}{$\begin{array}{l}\text { Model } 1 \text {, not adjusted for } \\
\text { treatment }^{\mathrm{a}}\end{array}$} & \multicolumn{2}{|c|}{$\begin{array}{l}\text { Model 2, adjusted for } \\
\text { treatment }^{\mathrm{a}}\end{array}$} \\
\hline & HR & $P$-value & HR & $P$-value \\
\hline \multicolumn{5}{|l|}{ Period of diagnosis } \\
\hline 1992-1999 & 1.8 & $<0.0001$ & 1.5 & $<0.0001$ \\
\hline 2000-2004 & 1.3 & 0.0005 & 1.3 & 0.003 \\
\hline $2005-2008^{\mathrm{b}}$ & 1.0 & & 1.0 & \\
\hline \multicolumn{5}{|l|}{ Age (years) } \\
\hline$<70^{\mathrm{b}}$ & 1.0 & & 1.0 & \\
\hline $70+$ & 1.4 & $<0.0001$ & 1.2 & 0.009 \\
\hline \multicolumn{5}{|l|}{ Gender } \\
\hline Males $^{\mathrm{b}}$ & 1.0 & & 1.0 & \\
\hline Females & 1.0 & 0.5 & 1.1 & 0.3 \\
\hline \multicolumn{5}{|l|}{ Comorbidity } \\
\hline No comorbidity ${ }^{\mathrm{b}}$ & 1.0 & & 1.0 & \\
\hline One comorbid condition & 1.0 & 0.7 & 1.1 & 0.6 \\
\hline Two or more comorbid conditions & 1.2 & 0.03 & 1.2 & 0.09 \\
\hline \multicolumn{5}{|l|}{ Depth of penetration, primary tumour } \\
\hline $\mathrm{T} 1,2$ & 0.6 & 0.004 & 0.6 & 0.004 \\
\hline $\mathrm{T} 3^{\mathrm{b}}$ & 1.0 & & 1.0 & \\
\hline $\mathrm{T} 4$ & 1.2 & 0.01 & 1.4 & 0.0006 \\
\hline \multicolumn{5}{|l|}{ Nodal status } \\
\hline NO & 0.7 & 0.0002 & 0.7 & 0.0002 \\
\hline $\mathrm{N} 1,2^{\mathrm{b}}$ & 1.0 & & 1.0 & \\
\hline \multicolumn{5}{|l|}{ Localisation of metastases } \\
\hline Liver only ${ }^{\mathrm{b}}$ & 1.0 & & 1.0 & \\
\hline Other & 0.9 & 0.006 & 0.9 & 0.02 \\
\hline \multicolumn{5}{|l|}{ Chemotherapy use } \\
\hline $\mathrm{No}^{\mathrm{b}}$ & & & 1.0 & \\
\hline Yes & & & 0.5 & $<0.0001$ \\
\hline \multicolumn{5}{|l|}{ Metastasectomy } \\
\hline $\mathrm{No}^{\mathrm{b}}$ & & & 1.0 & \\
\hline Yes & & & 0.5 & $<0.0001$ \\
\hline \multicolumn{5}{|l|}{ Resection of primary tumour } \\
\hline $\mathrm{No}^{\mathrm{b}}$ & & & 1.0 & \\
\hline Yes & & & 0.3 & 0.07 \\
\hline \multicolumn{5}{|l|}{ Radiotherapy directed at primary tumour } \\
\hline $\mathrm{No}^{\mathrm{b}}$ & & & 1.0 & \\
\hline Yes & & & 0.7 & $<0.0001$ \\
\hline \multicolumn{5}{|l|}{ Radiotherapy directed at metastases } \\
\hline $\mathrm{No}^{\mathrm{b}}$ & & & 1.0 & \\
\hline Yes & & & 1.2 & 0.2 \\
\hline
\end{tabular}

neoadjuvant chemotherapy [25-27]. The fact that survival tended to decrease over time among patients who did not receive chemotherapy can be explained by the large increase in chemotherapy administration rates, leaving behind the patients who are most frail, or have the most widespread disease. Younger patients ( $<70$ years) accounted almost fully for the observed increases in survival of the total group. Interestingly, males showed a much larger improvement in most recent years compared to females. This may be partly explained by a lower chemotherapy administration rate among females; we are not aware of gender-related differences in effectiveness of modern chemotherapy regimens.

After adjustment for patient- and tumour factors, a more recent period of diagnosis was associated with a lower hazard ratio (risk of death). After additional adjustment for 
relevant treatment modalities such as chemotherapy, a more recent period of diagnosis was still associated with a lower hazard ratio. This means that chemotherapy was not fully responsible for the improvements in survival. This means that other factors such as stage migration played an important part, which is not unexpected in view of the growing proportion of patients being diagnosed with metastatic disease. This means that an increasing proportion of patients is probably diagnosed with smaller and/or fewer metastatic lesions due to increasingly more effective imaging techniques. These patients, who tended to be wrongfully diagnosed as M0 patients in the past, have a better prognosis solely based on the less widespread extent of disease. Unfortunately, no on the size and number of metastatic lesions without lesions information was available in our study. Also the hazard ratios of specific treatment modalities have to be interpreted with caution, in view of the retrospective nature of this study; it is likely that selection of fitter patients for a certain treatment ('confounding by indication') has biased the results. For example, chemotherapy was associated with a hazard ratio of 0.5 , but this figure is biased in the context of a retrospective, non-randomised study as ours.

Our data show that with the increased use of chemotherapy and probably stage migration there was a decrease in local treatment with surgery, radiotherapy, or the combination of both therapies. Some authors have pled in favour of primary systemic chemotherapy in the treatment of metastatic rectal cancer and suggest that surgery and radiotherapy should be reserved for patients presenting with resectable metastatic disease or severe symptoms of bowel obstruction [28-30]. From our retrospective data, it is not possible to draw conclusions on any beneficial or harmful effect of the decreased resection rates of the primary tumour.

In conclusion, the results of this population-based study among patients with metastatic rectal cancer showed a relatively long median survival of patients without systemic treatment. The administration of chemotherapy increased from 5\% in 1992 to $61 \%$ in 2008, together with a reduction in the use of surgery and radiotherapy, while median survival improved from 38 to 53 weeks.

Open Access This article is distributed under the terms of the Creative Commons Attribution Noncommercial License which permits any noncommercial use, distribution, and reproduction in any medium, provided the original author(s) and source are credited.

\section{References}

1. IKCnet (2010) Dutch Comprehensive Cancer centres. http:// www.ikcnet.nl

2. Kapiteijn E, Marijnen CA, Nagtegaal ID et al (2001) Preoperative radiotherapy combined with total mesorectal excision for resectable rectal cancer. N Engl J Med 345:638-646
3. Elferink MA, van Steenbergen LN, Krijnen P et al (2010) Marked improvements in survival of patients with rectal cancer in the Netherlands following changes in therapy, 1989-2006. Eur J Cancer 46:1421-1429

4. Simmonds PC (2000) Palliative chemotherapy for advanced colorectal cancer: systematic review and meta-analysis. Colorectal Cancer Collaborative Group. BMJ 321:531-535

5. Meyerhardt JA, Mayer RJ (2005) Systemic therapy for colorectal cancer. N Engl J Med 352:476-487

6. Douillard JY, Cunningham D, Roth AD et al (2000) Irinotecan combined with fluorouracil compared with fluorouracil alone as first-line treatment for metastatic colorectal cancer: a multicentre randomised trial. Lancet 355:1041-1047

7. de Gramont A, Figer A, Seymour M et al (2000) Leucovorin and fluorouracil with or without oxaliplatin as first-line treatment in advanced colorectal cancer. J Clin Oncol 18:2938-2947

8. Hurwitz H, Fehrenbacher L, Novotny W et al (2004) Bevacizumab plus irinotecan, fluorouracil, and leucovorin for metastatic colorectal cancer. N Engl J Med 350:2335-2342

9. Kabbinavar FF, Hambleton J, Mass RD et al (2005) Combined analysis of efficacy: the addition of bevacizumab to fluorouracil/ leucovorin improves survival for patients with metastatic colorectal cancer. J Clin Oncol 23:3706-3712

10. Jonker DJ, O'Callaghan CJ, Karapetis CS et al (2007) Cetuximab for the treatment of colorectal cancer. N Engl J Med 357:2040 2048

11. Tol J, Koopman M, Cats A et al (2009) Chemotherapy, bevacizumab, and cetuximab in metastatic colorectal cancer. N Engl J Med 360:563-572

12. Meulenbeld HJ, van Steenbergen LN, Janssen-Heijnen ML et al (2008) Significant improvement in survival of patients presenting with metastatic colon cancer in the south of The Netherlands from 1990 to 2004. Ann Oncol 19:1600-1604

13. Meguid RA, Slidell MB, Wolfgang CL et al (2008) Is there a difference in survival between right- versus left-sided colon cancers? Ann Surg Oncol 15:2388-2394

14. Fritz A, Percy C, Jack A et al (2000) International classification of diseases for oncology. World Health Organization, Geneva

15. UICC (2002) TNM classification of malignant tumours. WileyLiss, New York

16. Koopman M, Antonini NF, Douma J et al (2007) Sequential versus combination chemotherapy with capecitabine, irinotecan, and oxaliplatin in advanced colorectal cancer (CAIRO): a phase III randomised controlled trial. Lancet 370:135-142

17. Charlson ME, Pompei P, Ales KL et al (1987) A new method of classifying prognostic comorbidity in longitudinal studies: development and validation. J Chronic Dis 40:373-383

18. Lemmens VE, Janssen-Heijnen ML, Verheij CD et al (2005) Co-morbidity leads to altered treatment and worse survival of elderly patients with colorectal cancer. Br J Surg 92:615623

19. Lemmens VE, van Halteren AH, Janssen-Heijnen ML et al (2005) Adjuvant treatment for elderly patients with stage III colon cancer in the southern Netherlands is affected by socioeconomic status, gender, and comorbidity. Ann Oncol 16:767-772

20. Feinstein AR, Sosin DM, Wells CK (1985) The Will Rogers phenomenon. Stage migration and new diagnostic techniques as a source of misleading statistics for survival in cancer. N Engl $\mathrm{J}$ Med 312:1604-1608

21. Glebov OK, Rodriguez LM, Nakahara K et al (2003) Distinguishing right from left colon by the pattern of gene expression. Cancer Epidemiol Biomarkers Prev 12:755-762

22. Li FY, Lai MD (2009) Colorectal cancer, one entity or three. J Zhejiang Univ Sci 10:219-229

23. Chiappa A, Makuuchi M, Lygidakis NJ et al (2009) The management of colorectal liver metastases: expanding the role of 
hepatic resection in the age of multimodal therapy. Crit Rev Oncol Hematol 72:65-75

24. Ruers T, Bleichrodt RP (2002) Treatment of liver metastases, an update on the possibilities and results. Eur J Cancer 38:1023-1033

25. Poston GJ, Adam R, Alberts S et al (2005) OncoSurge: a strategy for improving resectability with curative intent in metastatic colorectal cancer. J Clin Oncol 23:7125-7134

26. Nordlinger B, Benoist S (2006) Benefits and risks of neoadjuvant therapy for liver metastases. J Clin Oncol 24:4954-4955

27. Adam R (2003) Chemotherapy and surgery: new perspectives on the treatment of unresectable liver metastases. Ann Oncol 14(2): ii13-ii16
28. Reddy SK, Barbas AS, Clary BM (2009) Synchronous colorectal liver metastases: is it time to reconsider traditional paradigms of management? Ann Surg Oncol 16:2395-2410

29. Scheer MG, Sloots CE, van der Wilt GJ et al (2008) Management of patients with asymptomatic colorectal cancer and synchronous irresectable metastases. Ann Oncol 19:1829-1835

30. Temple LK, Hsieh L, Wong WD et al (2004) Use of surgery among elderly patients with stage IV colorectal cancer. J Clin Oncol 22:3475-3484 